\title{
Arequipeñismos y localismos en las tradiciones de Ricardo Palma
}

Por Soledad Maldonado Zedano 
Poeta, decana de la Facultad de Filosofía y Humanidades de la Universidad de San Agustín, Arequipa. Especialista en literatura Infantil. Doctora en Educación. 
"Bajo una gran ramada tenían establecidos sus reales el "chogni” López, que era el "chichero" de mayor fama".

"Muchos, muchísimos "bebes" habían consumido los parroquianos del "chogni” López, cuando se presentó el mejor "rasgueador" de "Quequeña”, a quien llamaban Marcos el "caroso"... y Andrés Moreno sacó a bailar a Fortunata Sotomayor la "Catiri". Entre los que formaban corro hallábase Perico Moreira el "Chiro"... Echó mano al alfiler y de un mete y saca... lo dejó «redondo».

Juana María Valladolid, "la Collota", porque le faltaban dedos en la mano, madre del infortunado Andrés Moreno; hallábase en la puerta... cuando un hombre jadeante - iPor Dios escóndame!... iAcabo de hacer una muerte y me persiguen! -Entre Ud.-.

Horrible lucha se entabló en el alma de aquella mujer. Había dado asilo al asesino de su hijo".

Ricardo Palma; Tradición; "Haz bien sin mirar a quien" (1737).

La voz "bebe" se refiere a vaso grande de chicha; "chogni" significa legañoso; "caroso" manchado; "Catiri" rubia; "Collota" manca o lisiada; "chiro" apodo de varón, que se parece a un pájaro. 
A cinco Leguas de Arequipa encuéntrase el pueblo de "Quequeña", donde el 6 de enero de 1737 celebrábase la fiesta de los Reyes Magos. Los habitantes habíanse dado cita en la alameda que une "Quequeña" con el caserío de "Yarabamba". Después de la procesión los concurrentes ocupáronse en visitar los puestos de vendimia, improvisados bajo los sauces, donde era preciso rendir culto al sabroso "picante" y a la confortadora "chicha" de maíz, que en ocasiones dadas ha sabido hacer de los arequipeños "heroicos leones".

El nombre del distrito de "Quequeña" viene del quechua "Kikiña", que significa: "Ya tronó" (del vocablo truenos). $\mathrm{Y}$ es el escenario de la moralizadora y cristiana Tradición de Don Ricardo Palma: "Haz bien sin mirar a quien". "Está ubicado a $30 \mathrm{~km}$. de Arequipa, en terrenos muy accidentados, con profusión de andenes Incas, para la agricultura, que se desprenden del volcán "Pichupichu". "Quequeña" es un lugar de frecuentes tempestades y descargas de rayos y truenos, con copiosas lluvias. Cuenta con un río que nace de la unión de dos: "Poroto y Uzuña"; además, de petroglifos notables que estiman los arqueólogos en 15000 años de antigüedad.

Pero también, Palma menciona, en su edificante historia, al caserío de "Yarabamba", nombre de las voces quechuas: "Yaro" planta espinosa y "Pampa" llanura; estando sus límites entre los pueblos de "Pocsi" y "Quequeña". En efecto Marco Martos comenta: "La tradición Lexicográfica en el Perú, en lengua castellana comienza al mismo tiempo que llegaron los españoles. Conocer realidades desconocidas para el mundo europeo obligó a los hablantes a incorporar numerosos vocablos de las lenguas aborígenes: Quechua y Aimara y a continuación de algunas lenguas que tuvieron vigencia en el Siglo XVI. Y así, vocablos mochicas, puquinas, tallanes, etc., se incorporaron al castellano del Perú. Fueron los cronistas, los soldados, nuestros primeros incipientes Lexicógrafos. Tiempo 
más tarde, los escritores simbólicos, colaboran, entre líneas con la tarea lexicográfica”.

Prosigue Marcos Martos: "Mas la tradición científica lexicográfica, a fines del siglo XIX cuenta con dos eximias personalidades: Pedro Paz Soldán y Unanue y Ricardo Palma, quienes sientan las bases de una lexicografía nacional (...) La pasión por investigar, por reconocer lo nuestro y definirlo, se mantiene intacta". Y agrega a lo ya mencionado: "La Lexicografía respecto a la literatura viene a ser como la fonética respecto de la semántica. Es base importante del manejo del idioma. Un escritor debe conocer todas las palabras que utiliza y percibir los matices de los vocablos". Luego, en el mismo exordio que comentara para el "Diccionario de Peruanismos" de Juan Álvarez Vita, del (2009), añade: "Los materiales que ahora nos entrega Álvarez Vita son de gran importancia, como lo fueron en otro tiempo los trabajos de Enrique Tovar; los tempranos estudios de Miguel Ángel Ugarte Chamorro sobre el léxico de Arequipa" (1942).

Las coordinaciones que establece Marco Martos entre la lexicografía y la Literatura nos conducen a establecer el carácter ruralista de nuestra literatura andina surperuana; que ha motivado la explosión de un género de creación poética muy practicado por los escritores locales de Arequipa; aunque no de gran prestigio, en opinión de algunos estudiosos como Juan Carpio Muñoz, esta práctica literaria de creación popular es denominada "Poesía Loncca Arequipeña".

La mención que hacemos a Juan Carpio Muñoz se sintetiza en su obra publicada con el nombre de Diccionario de Arequipeñismos, $2^{\text {da }}$ Edición 2012, que fundamentalmente está referido a un estudio, de muchos años, sobre el habla arequipeña. Afirma este autor: "La característica fundamental de la identidad cultural arequipeña es el mestizaje, la fusión de la cultura hispana y las 
autóctonas del sur del Perú. Las migraciones, especialmente de campesinos andinos, es una constante en nuestra historia, siendo los primeros pobladores los antiguos andinos de otras tierras de origen Altiplánico.

Este mestizaje, de síntesis, se manifiesta en primer lugar en el equilibrio, entre la naturaleza, la campiña y la vida rural frente a la ciudad o vida urbana. Además de los valores humanos como laboriosidad, perseverancia, honradez, civismo y una inquebrantable búsqueda y defensa de la libertad.

También, una serie de expresiones culturales propias, como la arquitectura, la música, la danza, la culinaria y, claro está, el habla. No sabemos con certeza, cuantas culturas florecieron en Arequipa. Suponemos los diversos aportes léxicos de los Tiahuanacos, los Collas, los Lupacas, los Juli, los Yanahuara, los Chuquibambas, los Yarabayas. Además, agregamos la lengua Puquina que se hablaba en los actuales distritos de Characato, Paucarpata, Mollebaya, Pocsi, Socabaya y otros. No obstante hace tres siglos que el puquina es lengua muerta. Del Aimara, lengua viva en el Altiplano, Perú-Bolivia, conocemos muchos vocablos como: Chachani, chaullar, chocollo, chuño, ñuto, pallapar, carca, catatar, quencha, ticte, etc. Anotemos que los Aimara hablantes, conocen su lengua como Aimará; (palabra aguda).

Del quechua proceden la mayoría de arequipeñismos, tanto que algunos quechuahablantes argumentan que los arequipeñismos no existen, pues solo serían palabras quechuas mal pronunciadas, o semánticamente deformadas en su significado. Sin embargo, sabemos que los españoles que conquistaron el Tahuantinsuyo y se establecieron en Arequipa ya encontraron que el quechua era síntesis de muchas vertientes idiomáticas preincas y luego Incas. El quechua era el idioma más difundido en estas tierras. 
Son, sin duda, numerosos los arequipeñismos que proceden del quechua. Los arequipeños de la ciudad y del campo somos hispanohablantes. Por tanto nuestro hablar popular y típico, está fusionado con giros propios de procedencia quechua y aimara. Tanto el hombre arequipeño como su hablar son mestizos por la contribución de pobladores chacareros y citadinos.

Con respecto a lo mencionado, en la tradición "Un obispo de contrabando" (1620) Ricardo Palma explica que la ciudad del Misti, que por entonces empezaba a llamarse así, es fruto del mestizaje. Palma afirma que el mestizo es fruto del connubio de india con español, siendo este, el mestizo, odiado por los nativos, quien, a su vez, es más cruel y soberbio que los propios españoles. El término mestizo, proveniente del vocablo quechua Misti, está referido a toda persona que no es "inkaika". Asimismo, en otros glosarios y entre los arequipeñismos se atribuye a Misti la significación de "Señor importante".

Además, el afán historiográfico de Palma por la fundación de Arequipa y su particularidades léxicas se reafirma en la tradición "Trampa para cazar ratones" (1715). Afirma Tito Cáceres Cuadros que Palma nos cuenta sobre un tacaño mayor, tendero en uno de los portales de San Agustín de Arequipa, "cuyo nombre no ha pasado a la posteridad pero los muchachos de la tierra del "mocontullo y del misquiricheo" lo bautizaron con el de Don Geripundio. El arequipeñismo "mocontullo" proviene de la voz quechua que significa hueso de la rodilla, que luego de cocinado era guardado cerca del fogón, para volver a ser utilizarlo y dar sustancia y sabor a las sopas o chupes arequipeños como el chaquetripas, chairos, locro de pecho, etc. Rómulo Cuneo Vidal comentaba que en las últimas décadas del siglo XIX y principios del XX se ironizaba a Arequipa como "Mocontullópolis", pues estas 
mistianas pedían a la vecina "Présteme Ud. su mocontullo para Misquirichir o dar sabor a mi chupe y cuando diga chis... se lo volveré". Este relato se consigna en el "Diccionario de Arequipeñismos" de Juan Guillermo Carpio Muñoz.

Como hemos apreciado, Palma caracteriza el hablar arequipeño como la tierra del "mocontuyo" y del "misquiricheo", además de otras tradiciones escritas con mucho sabor y con el mismo lenguaje arequipeño. Así, en "David y Goliath", estampa satírica, un bravucón que atemorizaba el distrito arequipeño de Miraflores es descalabrado por un pequeño David con piedra en mano; quien al tropezar con el hombre corpulento, es agredido a puntapiés diciéndole: -"Hijo de "cuchi”. ¿No "tenis" ojos"?- "iMiren quién habla! Dijo el borrico al mulo, "Tirte" allá orejudo. "El será hijo de cuchi".

Se verá que no es tan solo la graciosa anécdota sino el tratamiento del lenguaje con todas las inflexiones populares mistianas, dando lugar al mestizaje idiomático que pervive en la Arequipa de hoy desde antaño.

A despecho de algunos estudiosos regionales del sur peruano ¿es Ricardo Palma uno de los precursores de la llamada poesía loncca arequipeña? Pues tuvo una visión anticipada de las particularidades lingüísticas propias del mestizaje idiomático que era ostensible en suelo arequipeño. Es invalorable la capacidad de difusión de las Tradiciones Peruanas en América y el mundo, lo que nos permitió a los arequipeños poner en valor el habla popular de nuestras gentes; además de motivar el desarrollo de un género literario mestizo que nos caracteriza por el uso de arequipeñismos, localismos, términos lonccos y giros propios del habla arequipeña.

Son iniciadores de la poesía loncca o agraria destacados poetas como José Luis Bustamante y Rivero, Alberto Hidalgo, Alberto 
Guillén, Percy Gibson, Guillermo Mercado y los poetas lonccos Artemio Ramírez Bejarano, Isidro Zárate Santillana, Félix García Salas, Sebastián Oscco Dongo, además de múltiples autores y declamadores de esta poesía loncca arequipeña.

"Te traigo esta "qquepiñada"
de mis "lonccas" ilusiones
con el "ccayto" de mi esfuerzo
y un "pactuy" de mis amores
Estoy "ccotimbeando" alegre
con mi sombrero "huacali"
y mi pantalón "remangau"
pa'cantarte mi "hualali"

De Sentimientos Lonccos Artemio Ramírez Bejarano

Juan Guillermo Carpio Muñoz hace algunas aclaraciones necesarias: "Los mistis cusqueños se comunican entre ellos en castellano castizo. Cuando estos mismos mistis quieren comunicarse con los quechuahablantes, lo hacen en quechua fluido. De allí que es notorio el carácter bilingüe de los hablantes del Cusco y Puno. Pero no recurren a la mezcla de idiomas". Como sucede en Arequipa, que solo hablamos castellano. Mas en nuestra vida cotidiana y familiar, salpicamos el habla con voces motivadas por el quechua y aimara.

Aun siendo reconocida y múltiples veces creada y repetida la "poesía loncca arequipeña", está sobre todo en nuestras colectividades agrarias, populares, con autores autodidácticas. Afirma Carpio Muñoz: "En forma equivocada, al habla y a la poesía costumbrista de Arequipa se las califica de lonccas sin tener en consideración que son arequipeñismos, porque 
sus voces pertenecen, en origen y uso, tanto a los chacareros o lonccos, como a los habitantes de la ciudad. Lo que sucede es que en el presente se usan más en el agro que en la ciudad. $\mathrm{Si}$ actualmente entre los chacareros perviven las tradiciones de Arequipa, entre ellas las de su habla, es porque los lonccos se han convertido en la última trinchera de la identidad cultural arequipeña de antaño".

Pese a ello, el habla loncca de nuestros campesinos y habitantes de los distritos más antiguos y tradicionales persiste, aumentando el material poético y los sentimientos lonccos que son de gran preferencia del pueblo arequipeño:

- El "camayo", yo quisiera ser, de la chacra de tu corazón, "pa' humariarte" ioh, bella mujer! y después "taparte" el "boquerón”.

- ¿"Vo'sois" el que me "querís" pretender?

"botále" un "güeso" a la calle -Simón-, y "decile" que se vaya a entretener, porque "tuavía" tiene olor a "requesón".

- iAy, "cchichipa" te tengo que "merendar"!, aunque me cueste pisar espinas, sobre ellas "ti'hi" de "ccospiar".

- "Mirálo" el "pacpaco" me quiere enamorar, teniendo las rodillas "frontinas", y "tuito", el culo pa'remendar.

De El pretendiente Artemio Ramírez Bejarano 